\title{
Integrated Cloud-Aerosol-Radiation Product using CERES, MODIS, CALIPSO and CloudSat Data
}

\author{
Sunny Sun-Mack*a, Patrick Minnis ${ }^{\mathrm{b}}$, Yan Chen ${ }^{\mathrm{a}}$, Sharon Gibson ${ }^{\mathrm{a}}$, Yuhong $\mathrm{Yi}^{\mathrm{a}}$, Qing Trepte, \\ Bruce Wielicki ${ }^{\mathrm{b}}$, Seiji Kato ${ }^{\mathrm{a}}$, Dave Winker ${ }^{\mathrm{b}}$ \\ ${ }^{a}$ SSAI, 1 Enterprise Parkway, Suite 200, Hampton, VA USA 23666; \\ ${ }^{\mathrm{b}}$ Climate Science Branch, NASA Langley Research Center, Hampton, VA USA 23681
}

\begin{abstract}
This paper documents the development of the first integrated data set of global vertical profiles of clouds, aerosols, and radiation using the combined NASA A-Train data from the Aqua Clouds and Earth's Radiant Energy System (CERES) and Moderate Resolution Imaging Spectroradiometer (MODIS), Cloud-Aerosol Lidar and Infrared Pathfinder Satellite Observations (CALIPSO), and CloudSat. As part of this effort, cloud data from the CALIPSO lidar and the CloudSat radar are merged with the integrated column cloud properties from the CERES-MODIS analyses. The active and passive datasets are compared to determine commonalities and differences in order to facilitate the development of a 3dimensional cloud and aerosol dataset that will then be integrated into the CERES broadband radiance footprint. Preliminary results from the comparisons for April 2007 reveal that the CERES-MODIS global cloud amounts are, on average, 0.14 less and 0.15 greater than those from CALIPSO and CloudSat, respectively. These new data will provide unprecedented ability to test and improve global cloud and aerosol models, to investigate aerosol direct and indirect radiative forcing, and to validate the accuracy of global aerosol, cloud, and radiation data sets especially in polar regions and for multi-layered cloud conditions.
\end{abstract}

Keywords: MODIS, CALIPSO, CloudSat, CERES, clouds, radiation

\section{INTRODUCTION}

Understanding the effects of clouds on Earth's radiation balance, and particularly on longwave fluxes within the atmosphere, depends on having accurate knowledge of cloud vertical location within the atmosphere and their phase and ice/water content. Coincident profile information from CALIPSO's lidar and from CloudSat's radar offers a unique opportunity to map the vertical structure of clouds over the globe with accuracy never before realized. The combination of these data with observations from other A-train instruments, CERES ${ }^{1}$ and MODIS, will lead to new insight into cloud structure, aerosol climate effects, and more accurate estimates of surface longwave fluxes and atmospheric heating rate profiles that are needed to improve climate prediction. CloudSat and CALIPSO joined three satellites already in orbit (Aqua, Parasol, and Aura) to form a constellation of satellites known as the A-Train. Aqua was launched in May 4, 2002 while CALIPSO and CloudSat were launched in 28 April 2006. The A-train orbits are Sun-synchronous with a nominal orbital altitude of $705 \mathrm{~km}$ and inclination of 98 degrees. Aqua leads the constellation with an ascending node equatorial crossing time of about 1430 LT ( $₫ 15 \mathrm{~min})$. CALIPSO follows Aqua by 1-2 minutes and CloudSat by $10-15$ seconds, providing nearly simultaneous and collocated observations. This paper compares total, single-layer, and multilayer cloud amounts, cloud-top height, and cloud thickness among the CERES-MODIS, CALIPSO and CloudSat retrievals.

\section{DATA \& METHODOLOGY}

One of the primary CERES' products is the Single Scanner Footprint (SSF), which combines the CERES shortwave and longwave radiance measurements with the CERES-MODIS (CM) cloud properties. The 1-km pixel-level CM cloud

*Corresponding author address: Sunny Sun-Mack, szedung.sun-mack-1@nasa.gov; phone 1 757 951-1687. 
properties are convolved into the 20-km CERES scanner footprint to produce the best possible match between the cloud and aerosol properties and the measured broadband radiances. The CM cloud properties result from applying the CERES Aqua Edition 1 (Ed1) algorithms that detect clouds and retrieve a variety of parameters. Each 1-km MODIS pixel is initially classified as clear or cloudy using updated versions of the CM classification schemes ${ }^{2}$ that employ the 0.64 (visible), 2.1 (near infrared), 3.7 (solar infrared), 10.8 (infrared), and 12- $\mu \mathrm{m}$ (split window) radiances. The radiances are compared with predicted clear-sky radiances based on empirical estimates of spectral clear-sky albedo ${ }^{3-4}$ and skin temperatures from the NASA Goddard Data Assimilation Office (DAO) reanalysis adjusted using empirical estimates of spectral surface emissivity ${ }^{5-6}$ and atmospheric absorption calculated with the DAO vertical profiles of temperature and humidity. Effective droplet radius $r_{e}$ or effective ice crystal diameter $D_{e}$, optical depth $\tau$, ice or liquid water path IWP/LWP, effective cloud temperature $T_{e}$ and height $Z_{e}$, cloud thickness, and cloud phase are derived from these same radiances using one of three different techniques. The visible infrared solar-infrared split-window technique (VISST), an updated version of the original 3-channel daytime method ${ }^{7-8}$, is used during daytime, which is defined as the time when the solar zenith angle (SZA) is less than $82^{\circ}$. At other times of day, the solar-infrared infrared splitwindow technique (SIST) is used to determine each of the parameter values. The SIST, an improved version of the original 3-channel nighttime method ${ }^{7}$, only uses thermal and solar-infrared data. Thus, its retrievals are valid only for optically thin clouds. When the SIST is used, default values are used for all parameters except phase, Tc and Zc for clouds with $\tau<8$. The third method, adapted from Platnick et al. ${ }^{9}$, is designated the solar-infrared infrared nearinfrared technique (SINT) and is only applied to MODIS data during the daytime for clouds over snow or ice backgrounds. The $2.13-\mu \mathrm{m}$ channel on Aqua is used in the SINT to estimate $\tau$. Each method iteratively matches the observed radiances to TOA radiances calculated using emittance and reflectance parameterizations that account for atmospheric attenuation and surface reflectance and emission. The cloud reflectances and emittances are included in the parameterizations ${ }^{8,10}$ using updated lookup tables for each specific channel. The phase is selected based on the cloud temperatures, the availability of a solution, best consistency with a particular solution, and cloud altitude. The pixellevel data are then convolved with the individual broadband CERES radiative fluxes using the CERES footprint pointspread function to obtain each SSF data parcel. These SSF products include the cloud fraction and mean associated properties for up to two cloud layers.

The CALIPSO Cloud-Aerosol Lidar with Orthogonal Polarization (CALIOP) is a two-wavelength polarization-sensitive lidar that provides high-resolution vertical profiles of aerosols and clouds ${ }^{11}$. CALIOP utilizes three receiver channels: one measuring the 1064-nm backscatter intensity and two channels measuring orthogonally polarized components of the 532-nm backscattered signal. The fundamental vertical and horizontal sampling resolutions of CALIOP are 30 and 333 $\mathrm{m}$, respectively. CALIOP profiles are calibrated by normalizing the return signal to the predicted backscatter coefficients derived from meteorological observations in the aerosol-free region between 30 and $35 \mathrm{~km}$. Onboard calibration hardware is used to calibrate the $532-\mathrm{nm}$ perpendicular channel relative to the $532 \mathrm{-nm}$ parallel channel. The $1064-\mathrm{nm}$ channel is calibrated relative to the 532-nm total backscatter signal using optically thick cirrus clouds as reference targets.

CloudSat carries a nadir-viewing 94-GHz Cloud Profiling Radar (CPR) with 250-m vertical and $1.4 \mathrm{~km}$ horizontal resolutions. CPR measures the power backscattered from clouds as a function of distance from the CPR. The radar footprints are $1.4 \mathrm{~km}$ wide across track and $2.5 \mathrm{~km}$ along track with a spacing of $1.4 \mathrm{~km}$ between profiles and will therefore be more continuous than the higher resolution lidar data.

At present, the A-Train Data Depot at Goddard Earth Sciences Data and Information Services Center is operationally subsetting certain Aqua/MODIS Radiances and Atmospheres data along the CloudSat track. The CloudSat-collocated Aqua/MODIS subsets are provided in two flavors: narrow and wide swaths, correspondingly of about $\pm 5 \mathrm{~km}$ and \pm 100 $\mathrm{km}$ along CloudSat track. The subset data used in this paper are wide swath $( \pm 100 \mathrm{~km})$ data with geo-locations and the 1-km Aqua/MODIS Level 1B calibrated radiances. The CALIPSO and CloudSat products used in the comparisons are Vertical Feature Mask (VFM) and Cloud Scenario Classification (CLDCLASS) respectively. As indicated in figure 1, the three different data sources, MODIS, CALIPSO, and CloudSat, have very different horizontal resolutions: $1 \mathrm{~km}$, $333 \mathrm{~m}$ and $1.1 \mathrm{~km}$, respectively. Both CALIPSO VFM and CloudSat CLDCLASS are first collocated to each MODIS $1-\mathrm{km}$ pixel. Any CALIPSO shot or the center of the CloudSat profile that falls inside the MODIS 1-km pixel box is considered as collocated with the MODIS pixel. Figure 2 shows an example of the integrated clouds between CERESMODIS, CALIPSO and CloudSat for hour 8 of April 4, 2007. One month of merged data, April 2007, was processed and the results are summarized below. 


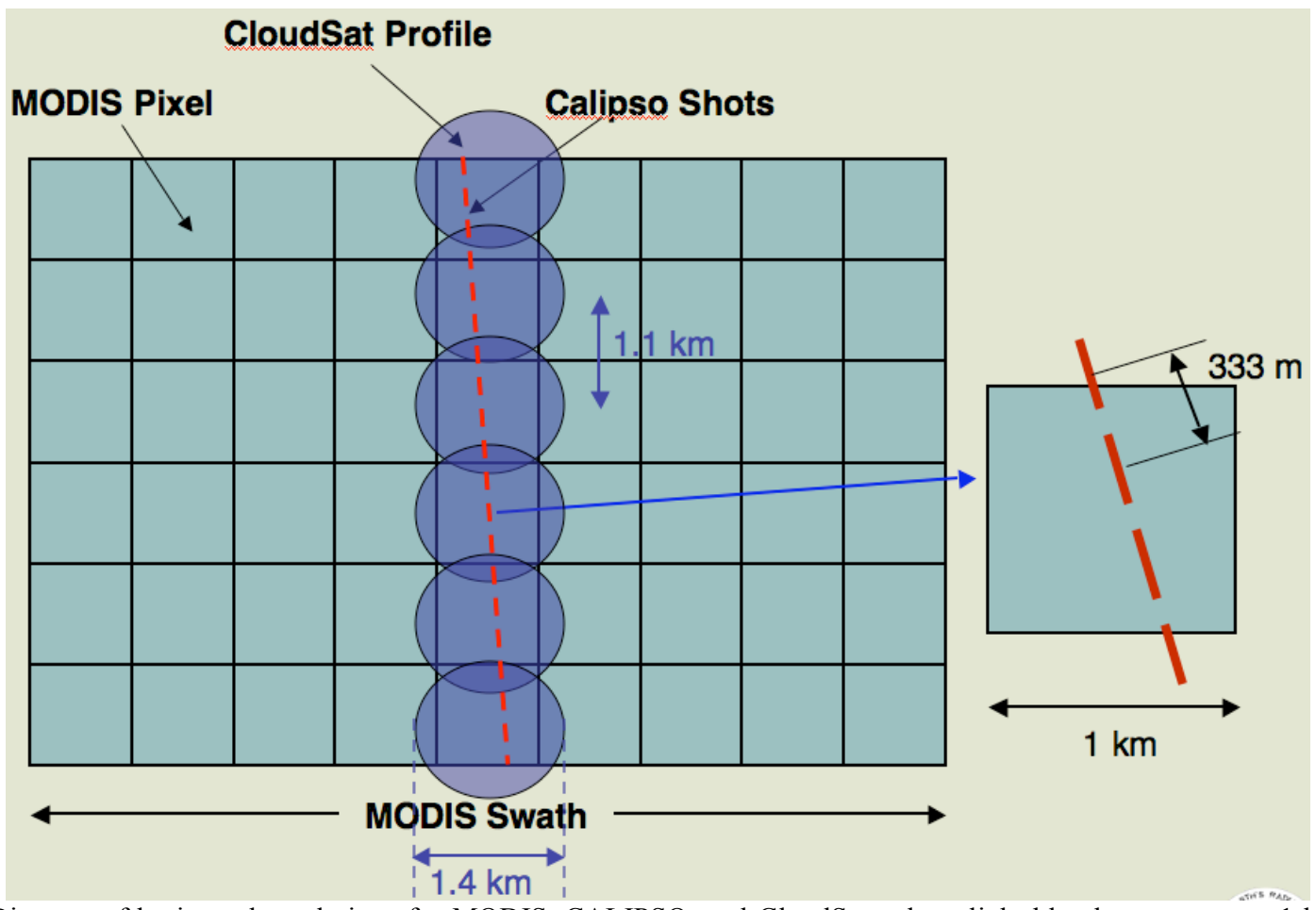

Figure 1: Diagram of horizontal resolutions for MODIS, CALIPSO, and CloudSat, where light blue box represents 1-km MODIS pixel, red dashed lines are CALIPSO shots with $333-\mathrm{m}$ horizonal resolution, and dark blue transparent circles are 1.1-km CloudSat profiles.

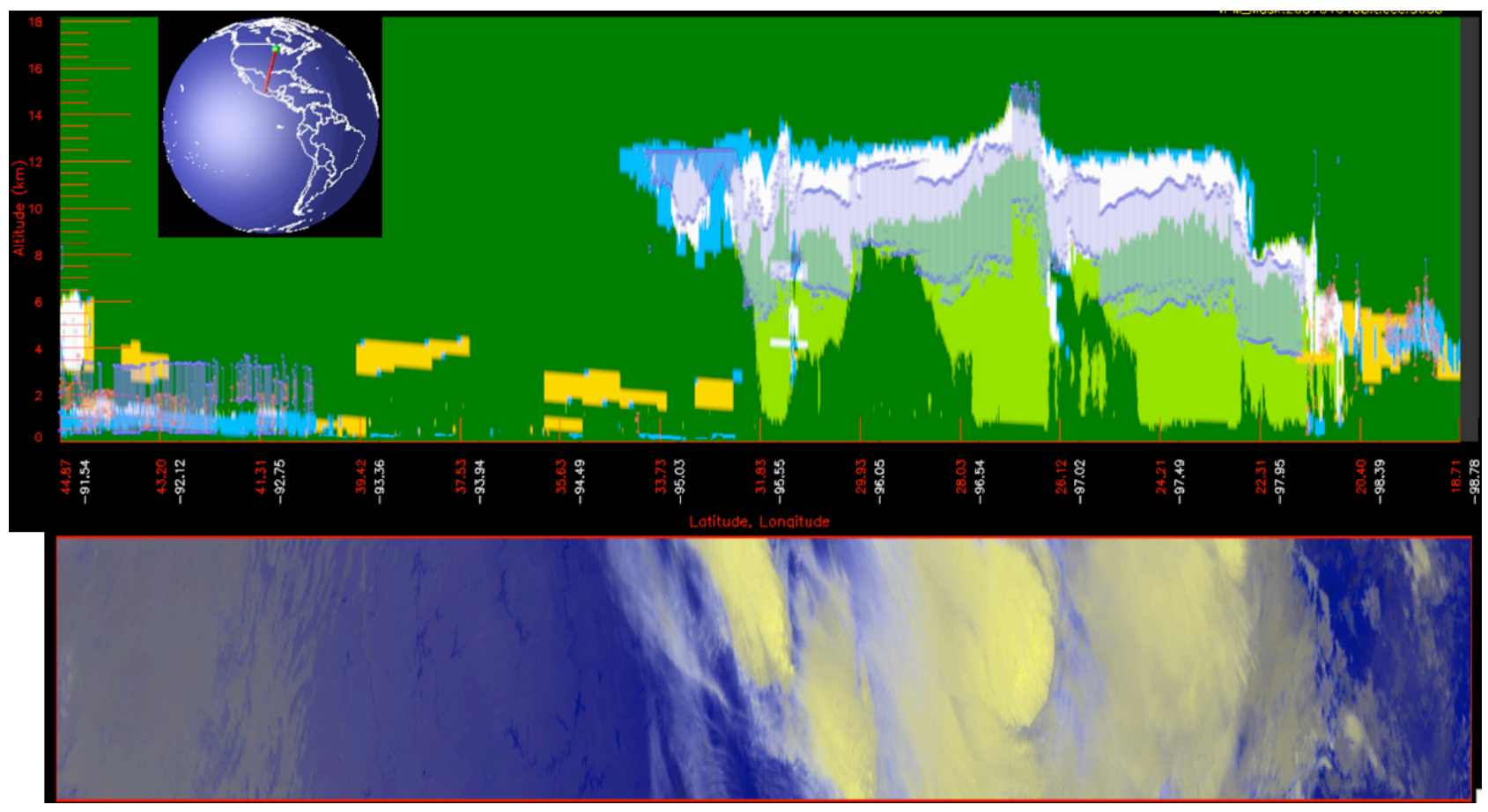

Figure 2: Integrated clouds from CERES-MODIS, CALIPSO VFM, and CloudSat CLDCLASS for 4 April 2007, hour 8. White denotes those clouds indicated by both CALIPSO and CloudSat,solid blue are CALIPSO clouds only,light green clouds by CloudSat only, and transparent clouds (blue: ice clouds, red: water clouds) are CERES clouds. Yellow is aerosol indicated by CALIPSO VFM. 


\section{RESULTS AND DISCUSSION}

\subsection{Cloud Fraction}

Latitudinal zonal cloud amount from April 2007 is shown on the left of Figure 3. CALIPSO detects the most clouds and CloudSat the least. CERES cloud fraction is just about half way between CALIPSO and CloudSat for all latitudinal zones except for the southern polar regions. Table 1 summarizes the cloud amount results for April 2007. Global cloud amount is 0.76 for CALIPSO, 0.62 for CERES and 0.47 for CloudSat. Over ocean at night, the CALIPSO cloud amount increases by 0.06 , CloudSat by 0.04 , and CERES remains more or less the same as during daytime. The right panel in Figure 3 shows both single-layer and multi-layer cloud fractions for April 2007, where the solid lines represent singlelayer (SL) and knotted lines denote multilayered (ML) clouds. CERES has two multi-layer detection methods: BTD (red) and CO2 (pink) multilayer algorithms ${ }^{12-14}$. Both Figure 3 and Table 3 show that the CALIPSO ML cloud fraction is 0.32 , while the rest are about $0.20-0.25$ lower. Despite the large differences in the multilayer fractions, all multilayer fractions show the same behavior; larger multilayer fractions occur in the polar regions and tropics than in mid-latitude regions.

Cloud Fraction April 2007, Day+Night, Land+Ocean

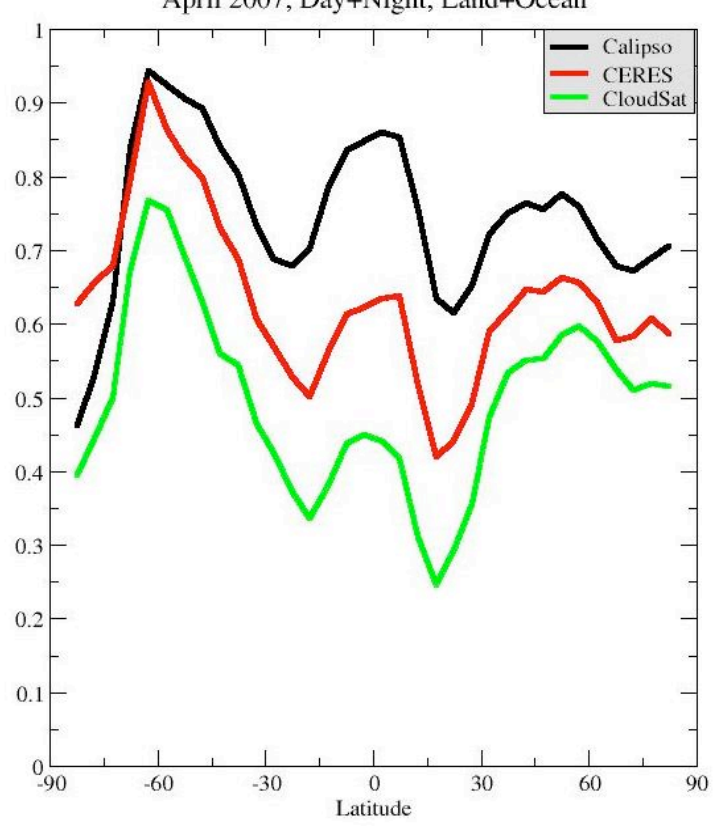

Cloud Fraction for Single and Multi Layer April 2007, Day+Night, Land+Ocean

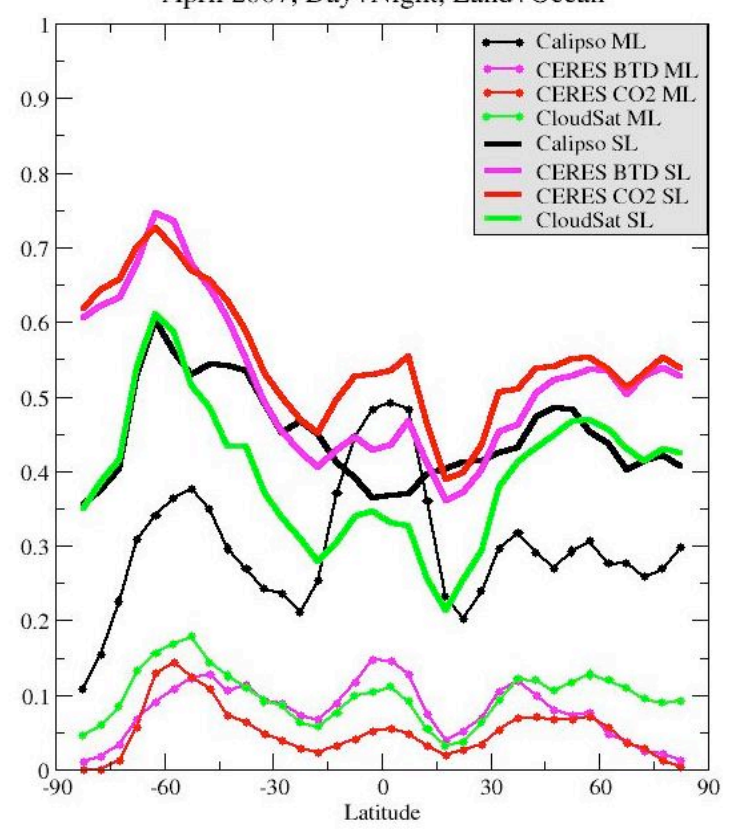

Figure 3: Left: Mean cloud fractions from CALIPSO (black line), CERES (red) and CloudSat (green) for April 2007. Right: Mean single layer (solid lines) and multilayer (knotted lines) cloud fractions.

Table 1: Global cloud fraction among CERES, CALIPSO and CloudSat separated by Day/Night and Ocean/Land for April $2007 .$.

\begin{tabular}{|c|c|c|c|c|c|c|c|c|c|}
\hline & \multicolumn{3}{|c|}{ CERES } & \multicolumn{3}{c|}{ CALIPSO } & \multicolumn{3}{c|}{ CloudSat } \\
\hline & Day & Night & All & Day & Night & All & Day & Night & All \\
\hline Ocean & 0.66 & 0.65 & 0.65 & 0.77 & 0.83 & 0.80 & 0.47 & 0.51 & 0.49 \\
\hline Land & 0.55 & 0.54 & 0.55 & 0.71 & 0.69 & 0.70 & 0.43 & 0.43 & 0.43 \\
\hline All Scene & 0.62 & 0.61 & 0.62 & 0.75 & 0.78 & 0.76 & 0.46 & 0.48 & 0.47 \\
\hline
\end{tabular}

Table 2: Same as Table 1, except for single layer results.

\begin{tabular}{|c|c|c|c|c|c|c|c|c|c|c|c|c|}
\hline & \multicolumn{3}{|c}{ CERES BTD } & \multicolumn{3}{c|}{ CERES CO2 } & \multicolumn{3}{c|}{ CALIPSO } & \multicolumn{3}{c|}{ CloudSat } \\
\hline & Day & Night & All & Day & Night & All & Day & Night & All & Day & Night & All \\
\hline Ocean & 0.49 & 0.58 & 0.54 & 0.54 & 0.60 & 0.57 & 0.45 & 0.49 & 0.47 & 0.37 & 0.40 & 0.39 \\
\hline Land & 0.33 & 0.44 & 0.39 & 0.42 & 0.49 & 0.46 & 0.39 & 0.38 & 0.39 & 0.35 & 0.35 & 0.35 \\
\hline All Scene & 0.44 & 0.53 & 0.49 & 0.50 & 0.56 & 0.53 & 0.43 & 0.46 & 0.45 & 0.37 & 0.38 & 0.37 \\
\hline
\end{tabular}


Table 3: Same as Table 1, except for multilayer results.

\begin{tabular}{|c|c|c|c|c|c|c|c|c|c|c|c|c|}
\hline & \multicolumn{3}{|c|}{ CERES BTD } & \multicolumn{3}{c|}{ CERES CO2 } & \multicolumn{3}{c|}{ CALIPSO } & \multicolumn{3}{c|}{ CloudSat } \\
\hline & Day & Night & All & Day & Night & All & Day & Night & All & Day & Night & All \\
\hline Ocean & 0.11 & 0.07 & 0.09 & 0.06 & 0.05 & 0.06 & 0.32 & 0.34 & 0.33 & 0.10 & 0.11 & 0.10 \\
\hline Land & 0.13 & 0.08 & 0.10 & 0.07 & 0.04 & 0.05 & 0.32 & 0.31 & 0.31 & 0.09 & 0.08 & 0.08 \\
\hline All Scene & 0.11 & 0.07 & 0.09 & 0.06 & 0.04 & 0.05 & 0.31 & 0.32 & 0.32 & 0.10 & 0.10 & 0.10 \\
\hline
\end{tabular}

\subsection{Cloud Top Height}

Figure 4 shows the daytime single-layer cloud-top height frequencies (left side) from CERES, CALIPSO and CloudSat for the southern hemisphere mid-latitude zone (SM: $30^{\circ} \mathrm{S}$ to $60^{\circ} \mathrm{S}$ ) over ocean for April 2007. Figure 4 indicates that all three datasets retrieve the most single-layer cloud tops at altitudes between 1 and $2 \mathrm{~km}$ over ocean. The cloud altitude is divided into three sections: low clouds $(0-4 \mathrm{~km})$, middle clouds $(4-8 \mathrm{~km})$, and high clouds (above $8 \mathrm{~km})$. The cloud height differences among CERES, CALIPSO and CloudSat for the three cloud height ranges are shown in the right panel of Figure 4. For low clouds $(0-4 \mathrm{~km})$ the occurrence percentage in cloud-top height difference within $\pm 0.5 \mathrm{~km}$ between CALIPSO and CERES $\mathrm{km}$ is $52 \%, 91 \%$ for CALIPSO and CloudSat, and $46 \%$ for CloudSat and CERES. The mean differences are $0.5 \mathrm{~km}$ between CALIPSO and CERES with CERES being higher (low clouds), $0.32 \mathrm{~km}$ between CALIPSO and CloudSat with CloudSat being higher. For middle and high clouds, the difference frequency curve broadens and the greatest frequency of occurrence moves toward larger differences with CALIPSO being higher. The same trend is true for both CALIPSO-CloudSat and CloudSat-CERES. Figure 5 is the same as Figure 4, except that data were taken over land in the northern hemisphere mid-latitude zone (NM: $30^{\circ} \mathrm{N}$ to $60^{\circ} \mathrm{N}$ ). In contrast to ocean, the single layer clouds show two distinct altitude peaks in all three datasets. CALIPSO shows maximum frequencies at 2.3 and 11 $\mathrm{km}$ compared to 3.0 and $9.5 \mathrm{~km}$ for CloudSat, and 2.0 and $10.2 \mathrm{~km}$ for CERES.

Top Height (km)

200704 Ocean SM DayTime

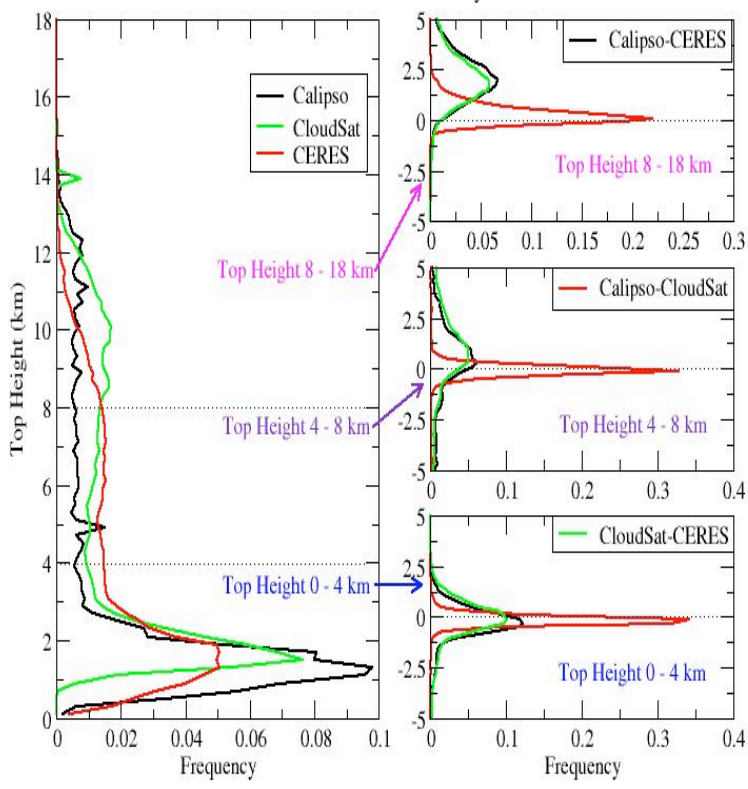

Figure 4: Left panel: Single-layer cloud top height occurrences for CERES (red), CALIPSO (black) and CloudSat (green) for Southern Hemisphere mid-latitude zone $\left(30^{\circ} \mathrm{S}-60^{\circ} \mathrm{S}\right)$ over ocean during daytime for April 2007.

Right panel: Single-layer cloud top height difference frequencies for CALIPSO-CERES (black), CALIPSO-CloudSat (red), and CloudSat-CERES (green).

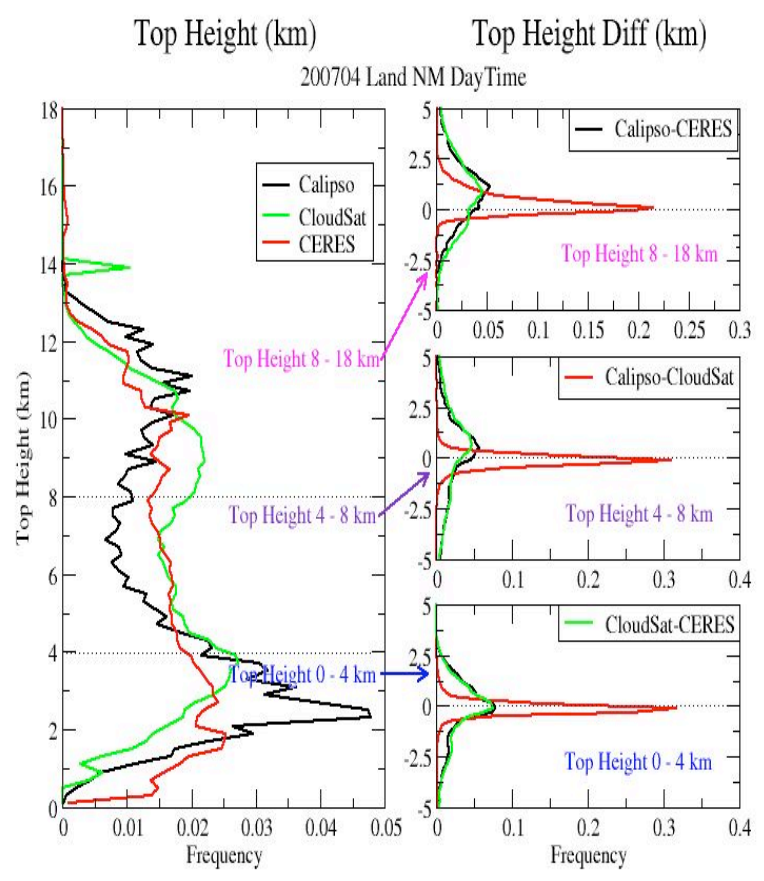

Figure 5: Same as Figure 4, except over land for Northern Hemisphere mid-latitude zone $\left(30^{\circ} \mathrm{N}\right.$ to $\left.60^{\circ} \mathrm{N}\right)$. 
The pyramid shapes shown in Figure 6 are the mean zonal single-layer cloud-top height difference densities as functions of cloud altitude for April 2007. The left and right side panels are for ocean and land, respectively. Clouds over the Tropics are the highest, reaching up to $18 \mathrm{~km}$ over both ocean and land. Cloud altitude decreases from the Tropics to the Polar regions forming a pyramidal shape in the plots. The top panels are for CALIPSO-CERES with colors representing cloud top height differences ranging from $-1.5 \mathrm{~km}$ (dark blue) to $8.5 \mathrm{~km}$ (red). For low clouds $(<4 \mathrm{~km}$ ), the CERES cloud-top heights agree with their CALIPSO counterparts very well, mostly within $\pm 0.5 \mathrm{~km}$ except in the polar regions where CALIPSO detects clouds at lower altitudes. The largest discrepancy occurs over the Tropics when cloud top altitude is between 15 and $18 \mathrm{~km}$. In that case, CALIPSO detects high thin cirrus with very low optical depths, which CERES probably misses altogether or misplaces at much lower altitudes. The middle panels of Figure 6 are for CALIPSO - CloudSat, where the agreement (Figure 6) is very good from $1-9 \mathrm{~km}$. However for clouds lower than 1 $\mathrm{km}$, CloudSat about $1 \mathrm{~km}$ higher than CALIPSO. The bottom panels of Figure 6 are for CloudSat - CERES, where the top layer of the pyramid shows much better agreement compared with CALIPSO - CERES results.

\subsection{Cloud Thickness}

Figure 7 shows cloud thickness frequencies of occurrence (top figure) and cloud thickness difference occurrence frequencies (bottom three figures) for single-layer clouds over tropical ocean during daytime for April 2007. The CALIPSO (black) data in Figure 7 (top) indicate that a cloud thickness of about $0.55 \mathrm{~km}$ is most common, while $0.3-\mathrm{km}$ thick clouds occur most frequently in the CloudSat (green) data. A 0.1-km thick cloud is most common in the CERES (red) estimates. However the range of cloud thickness is very broad, up to 3-4 km thick for both CALIPSO and CloudSat. For CERES, the frequency of cloud thickness decreases almost monotonically, a secondary peak occurs at 0.5 $\mathrm{km}$ with increasing thickness. The cloud thickness differences among CALIPSO, CERES and CloudSat are shown in Figure 7 (bottom) for the three different cloud altitude ranges defined in section 3.2. The black line in these plots represents single layer cloud thickness difference between CALIPSO and CERES, the red line denotes CALIPSOCloudSat, and green line is for CloudSat-CERES. For low clouds, the mean thickness difference between CALIPSO and CERES is $0.13 \mathrm{~km}$ with CALIPSO being slightly thicker. On average, CloudSat clouds are $0.19 \mathrm{~km}$ thicker than those from CALIPSO and $0.18 \mathrm{~km}$ thicker than the CERES values. The thicker CloudSat clouds are expected because the CloudSat radar can penetrate deeper into thick clouds than CALIPSO. The variations in the differences result form different matching among the three datasets. For mid-level clouds, the mean CERES cloud thickness is $0.15 \mathrm{~km}$ greater than that from CALIPSO. The CloudSat mid-level clouds are, on average, $1.8 \mathrm{~km}$ thicker than their CALIPSO counterparts. CloudSat and CERES midlevel thicknesses differ, in the mean, by $1.9 \mathrm{~km}$. In this study, precipitation contiguous with the cloud detected by CloudSat is considered as part of the cloud, so neither CALIPSO nor CERES would include the precipitation depth as part of the cloud. For high clouds, the mean thickness difference between CALIPSO and CERES is $0.01 \mathrm{~km}$. Again, the CALIPSO clouds $1.7-\mathrm{km}$ thinner than those from CloudSat, while the CERES clouds are 1.9-km thinner. Precipitation and penetration depth differences give rise to the discrepancies between CloudSat and CALIPSO. The agreement of single layer cloud thickness between CALIPSO and CERES is remarkable, regardless cloud altitude. Figure 8 shows the tropical results for cloud thickness over land. The results are very similar to those over ocean.

The global averaged cloud thickness difference percentages are shown in Figure 9, for five thickness ranges: (1) thickness difference less than $-1.5 \mathrm{~km},(2)-1.5$ to $-0.5 \mathrm{~km},(3)-0.5$ to $+0.5 \mathrm{~km},(4)+0.5$ to $+1.5 \mathrm{~km}$, (5) greater than + $1.5 \mathrm{~km}$. The top, middle, and bottom panels represent high, mid and low cloud altitudes, respectively. For low-level clouds, the agreement between CALIPSO and CERES within $-0.5-0.5 \mathrm{~km}$ is $63 \%$, same for CALIPSO-CloudSat, and $53 \%$ for CloudSat -CERES. For higher cloud altitude, $43 \%$ of CloudSat clouds are at least $1.5 \mathrm{~km}$ thicker than CALIPSO, 54\% are thicker than the CERES values, while 34\% of the CERES clouds are in agreement with CALIPSO.

The good thickness agreement between CALIPSO and CERES is also demonstrated in Figure 10. Figure 10 shows the single layer zonal cloud thickness difference densities among CALIPSO, CERES and CloudSat as functions of CALIPSO cloud altitude during daytime over ocean and land for April 2007. The left, middle, and right panels are for CALIPSO-CERES, CloudSat-CALIPSO, and CloudSat-CERES, respectively, with the colors representing cloud thickness differences ranging from $-4.5 \mathrm{~km}$ (dark blue) to $5.5 \mathrm{~km}$ (red). Green denotes thickness differences in agreement to within -0.5 to $0.5 \mathrm{~km}$. As seen in Figure 10, the CERES cloud thickness compares very well with CALIPSO for most of clouds up to 6-7 km cloud altitude, except in polar regions. The CERES clouds are about 1-km thicker than the CALIPSO values for clouds between 7 and $10 \mathrm{~km}$. The yellow outer layer around the left panel 

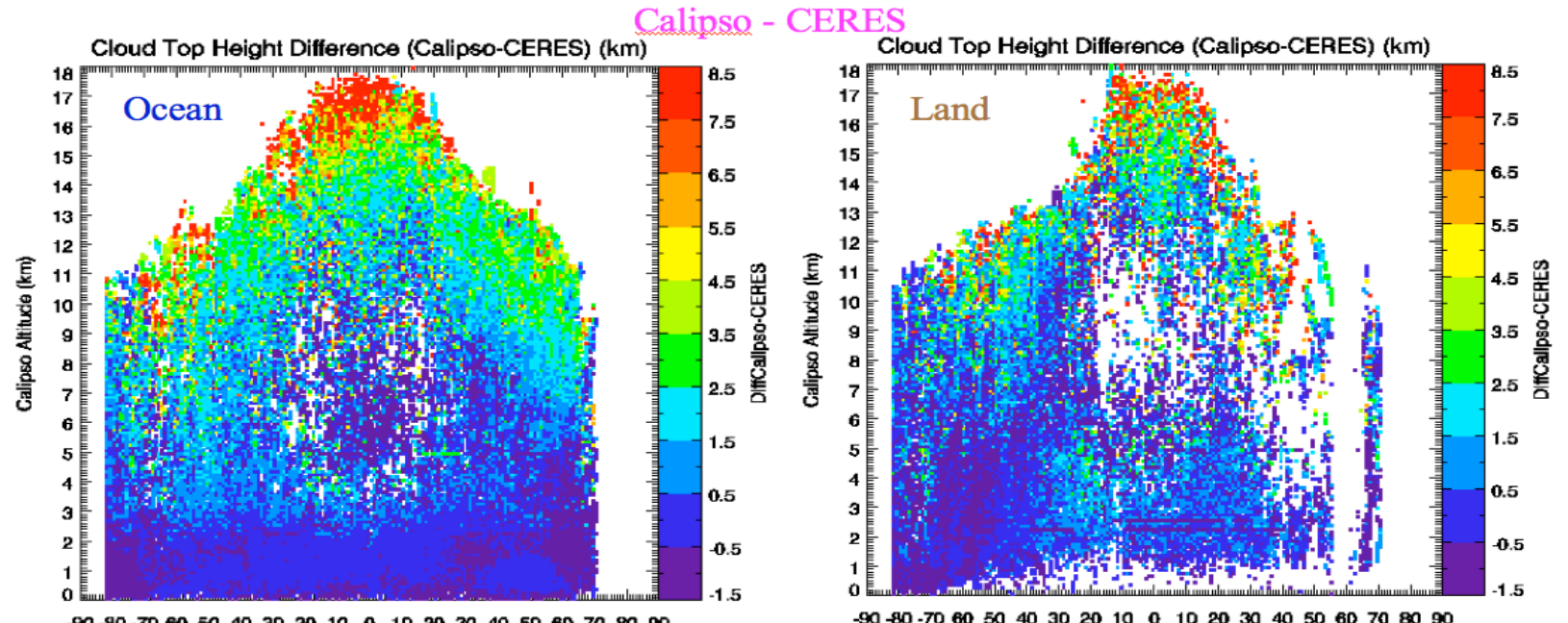

$-90-80-70605040 \quad 302010 \quad 0 \quad 1020304050607080 \quad 90$

$-90-80-706050403020100102030405060708090$

Latitute

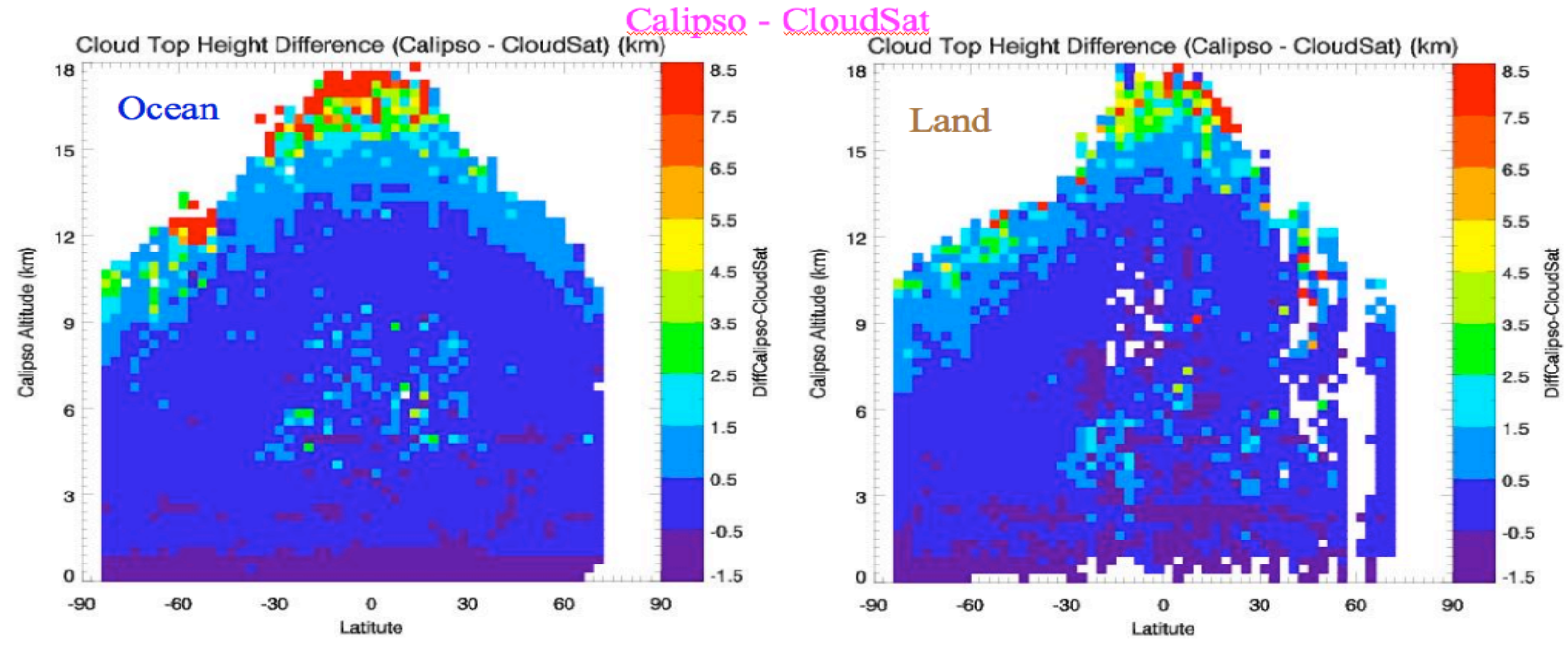

CloudSat - CERES
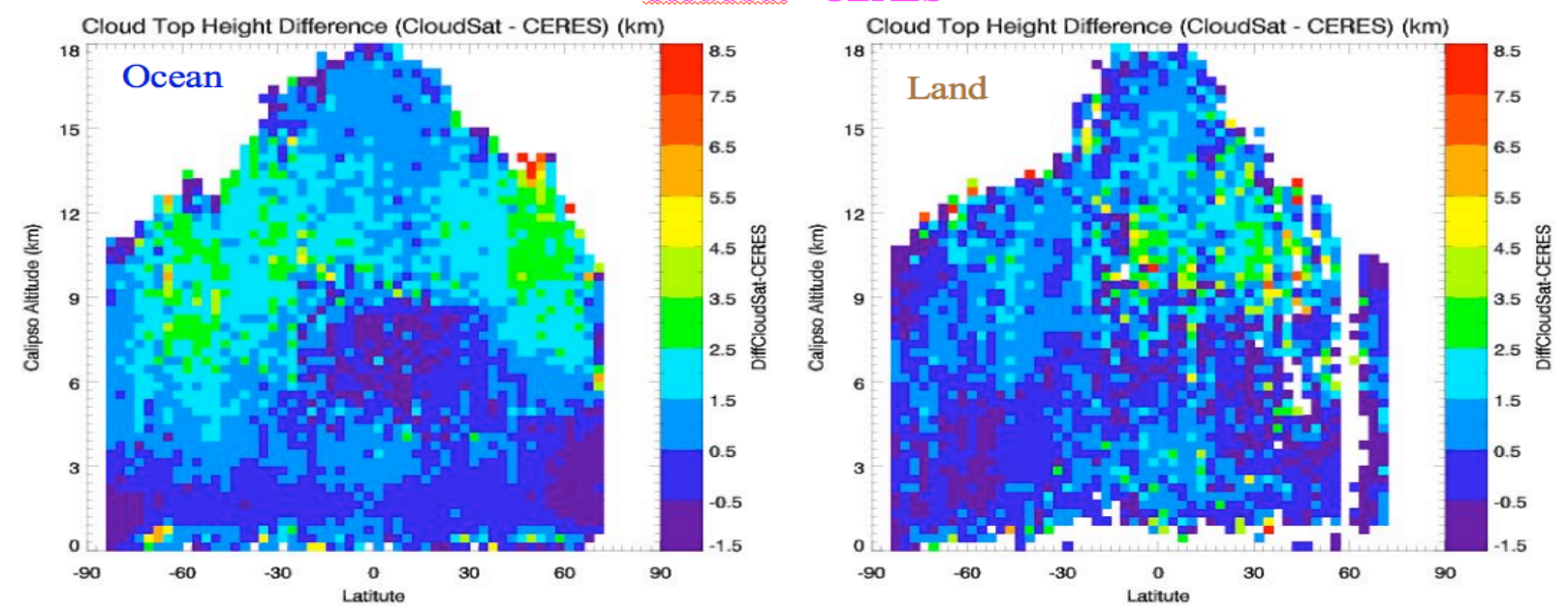

Figure 6: Zonal single layer cloud top height difference density as a function of cloud altitude for April 2007. Left panels are for ocean and right for land. Top panels are for CALIPSO-CERES, middle panels for CALIPSO-CloudSat and bottom panels for CloudSat-CERES with colors representing cloud top height differences ranging from $-1.5 \mathrm{~km}$ (dark blue) to $8.5 \mathrm{~km}$ (red). 


\section{Cloud Thickness Frequency}

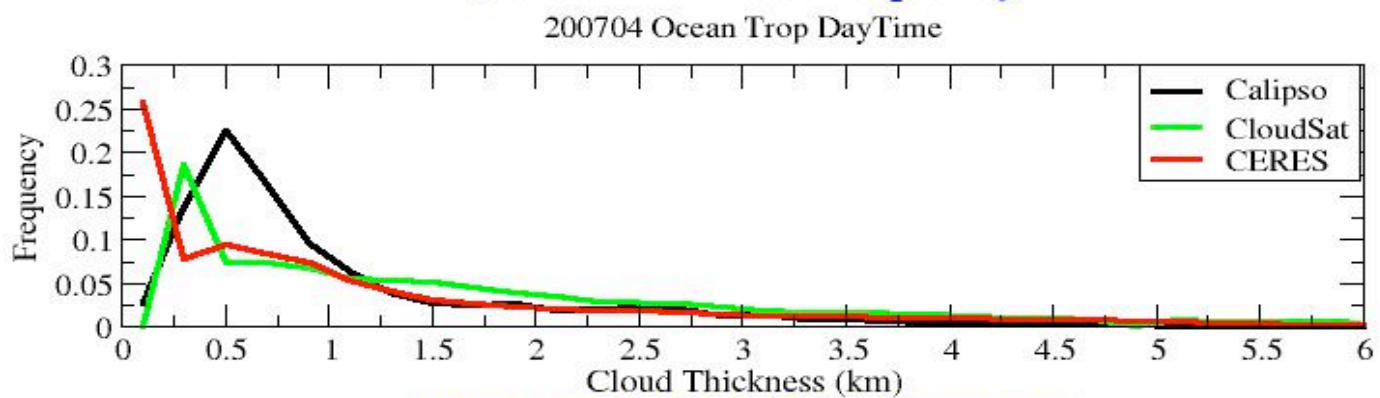

Cloud Thickness Difference Frequency
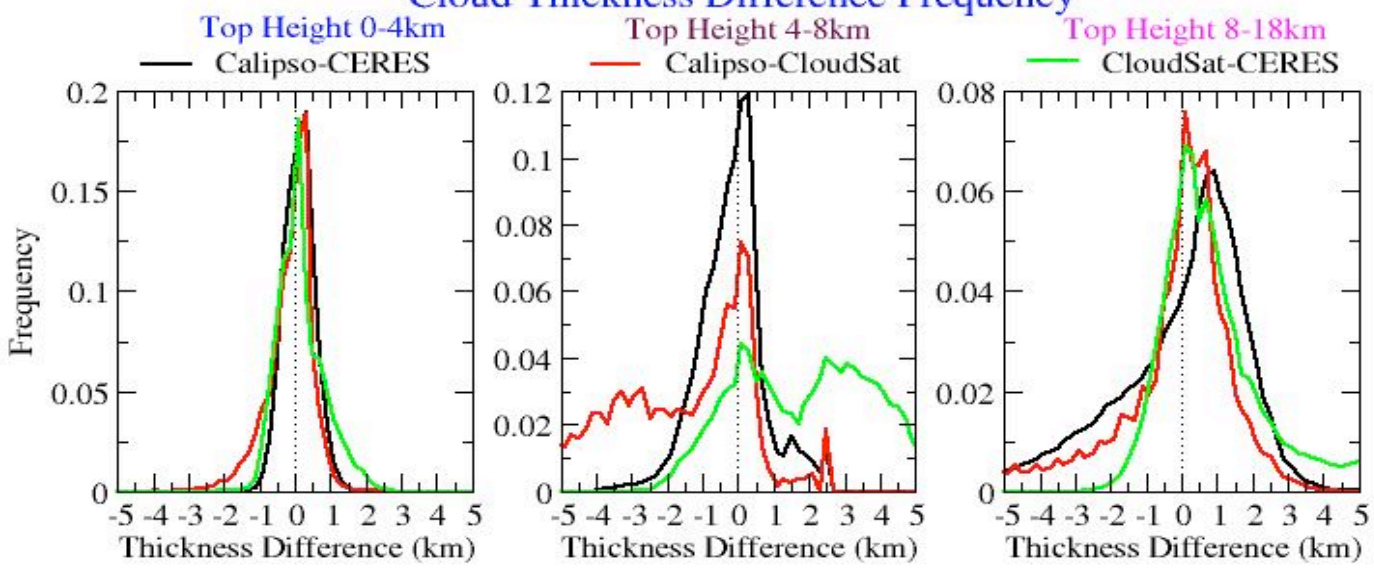

Figure 7: Cloud thickness frequency (top figure) and cloud thickness difference frequency of occurrence (bottom three figures) for single clouds over tropical ocean during daytime for April 2007.

Cloud Thickness Frequency

200704 Land Trop DayTime

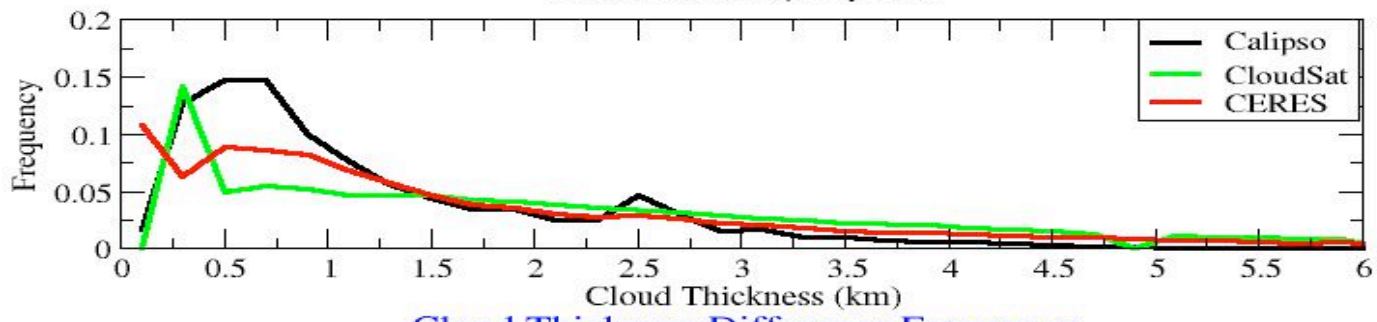

Cloud Thickness Difference Frequency
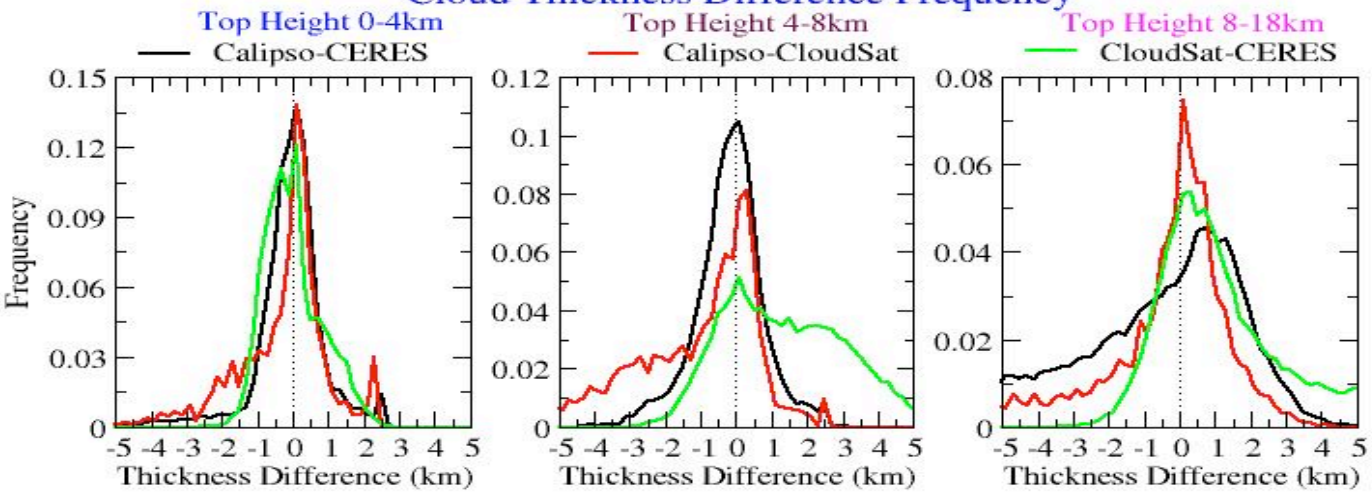

Figure 8: Same as Figure 7, except over land. 


\section{Global Cloud Thickness Difference Percentage (\%)}
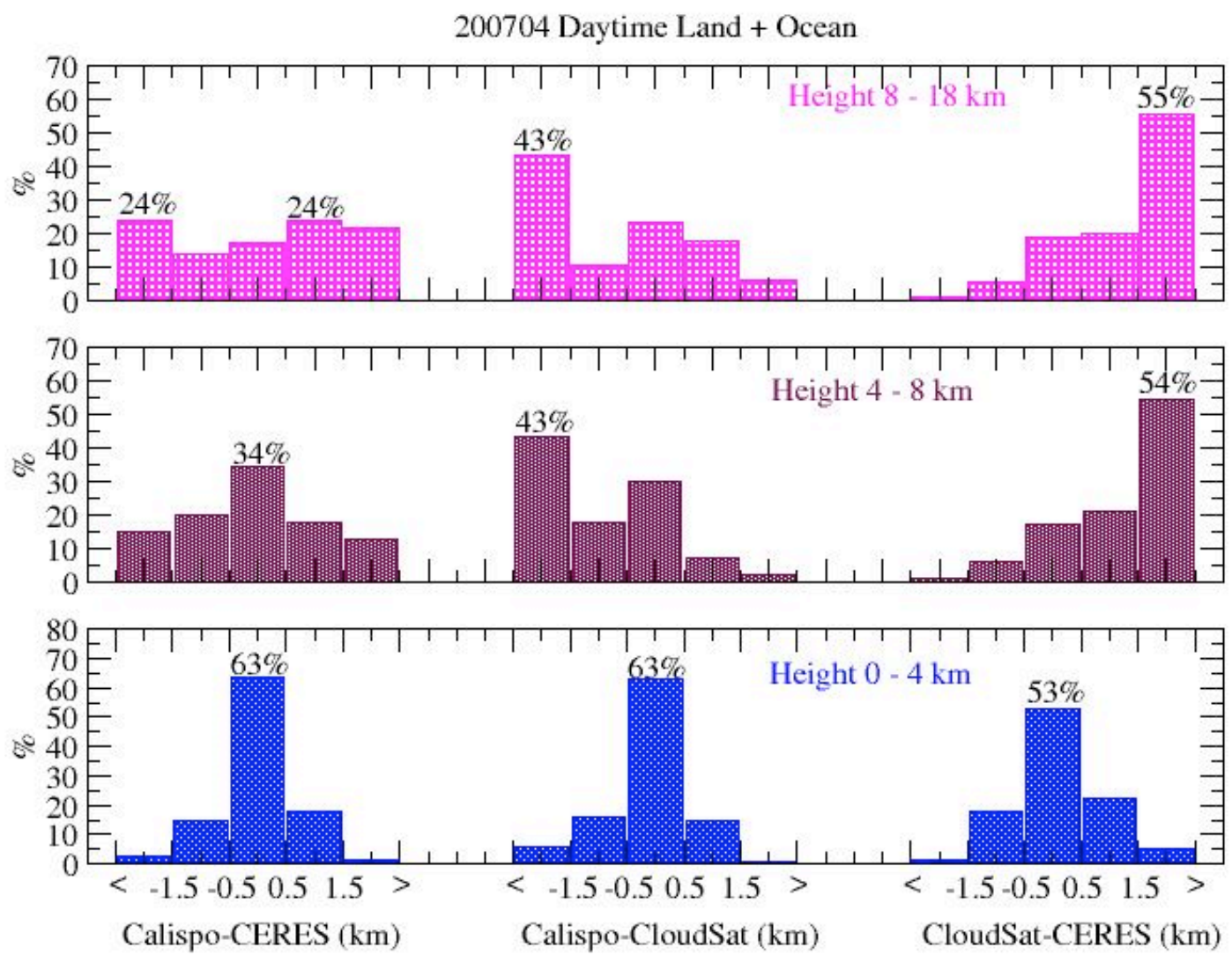

Figure 9: Global cloud thickness difference percentages for 5 thickness ranges. Top, mid and low panels represent high, mid and low cloud altitudes respectively.
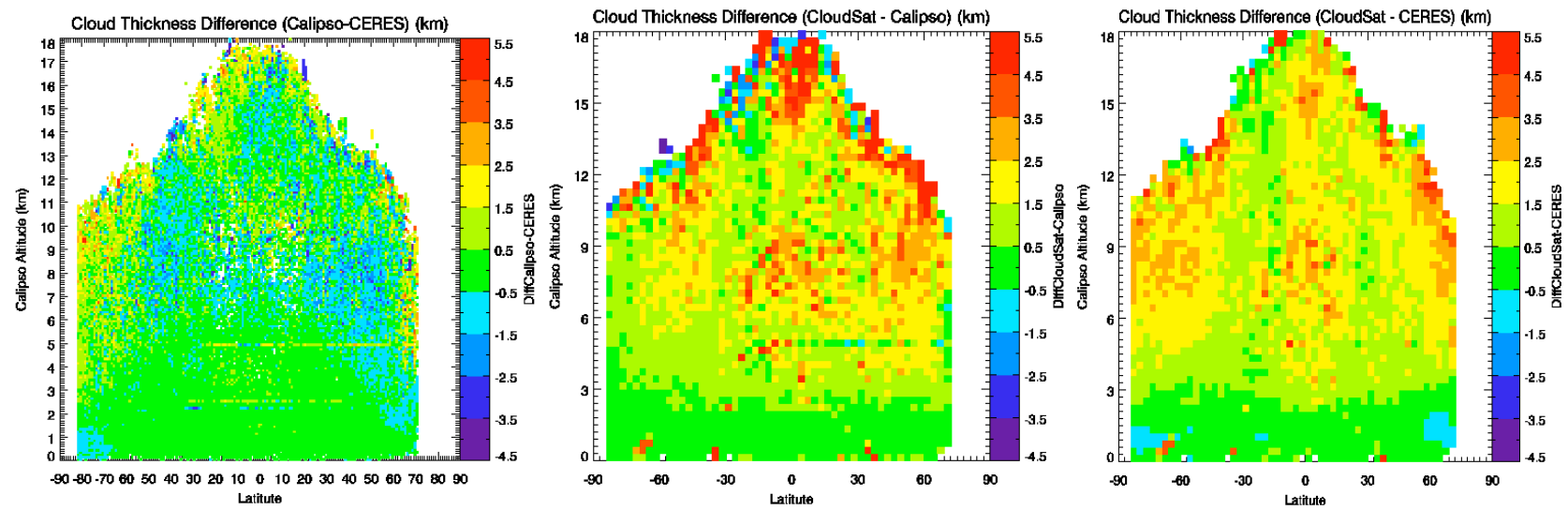

Figure 10: Zonal single layer cloud thickness difference densities among CALIPSO, CERES and CloudSat as functions of cloud altitude during daytime over ocean and land for April 2007. Left: CALIPSO-CERES, middle: CloudSat-CALIPSO, and right: CloudSat-CERES. Colors represent cloud thickness differences from $-4.5 \mathrm{~km}$ (dark blue) to $5.5 \mathrm{~km}$ (red) 
pyramid indicates those CALIPSO clouds that are about $2 \mathrm{~km}$ thicker than those from CERES. The agreement between the CALIPSO and CloudSat thicknesses is high for low-level clouds $(<3 \mathrm{~km})$. At higher altitudes, CloudSat thicknesses are about 1-2 km thicker those from CALIPSO. At the top edge of the plot, the CloudSat clouds are about $4 \mathrm{~km}$ thicker than CALIPSO. While it is clear that the CERES cloud thickness estimates can use some additional refinement, the current parameterizations ${ }^{15,16}$ based on very limited surface-based radar and lidar datasets are surprisingly accurate.

\section{CONCLUSIONS}

Results from the CERES Aqua-MODIS Ed1 cloud analyses and the CALIPSO VFM and CloudSat CLDCLASS schemes were merged using a recently developed method. Cloud fraction, single layer cloud fraction, multilayer cloud fraction, cloud top height and cloud thickness were compared among the merged CERES-MODIS, CALIPSO and CloudSat datasets. The global cloud fractions from CALIPSO, CloudSat, and CERES are 0.76, 0.47, and 0.62, respectively. CALIPSO detects many more optically thin clouds than the other two approaches, accounting for the large differences among them. The CALIPSO multilayer cloud fraction is 0.32; both CERES and CloudSat detect much less multilayered cloudiness: $\sim 0.1$. For stratus clouds, the CERES cloud-top height compares very well with CALIPSO being within $0.5 \mathrm{~km}$. The CloudSat cloud-top height compares very well with CALIPSO for all clouds with altitudes between 1 and $10 \mathrm{~km}$, with CloudSat being higher for cloud altitude $<1 \mathrm{~km}$ and CALIPSO being higher when cloud altitude $>10 \mathrm{~km}$. Agreement in cloud thickness between CERES and CALIPSO is seen for both low and middle level clouds (up to $8 \mathrm{~km}$ ). Comparison in cloud thickness between CALIPSO and CloudSat yields lower agreement. CloudSat is much thicker than both CALIPSO and CERES by $1.5 \mathrm{~km}$ or more. These preliminary results provide guidance for a more refined analysis that will separate precipitating and non-precipitating clouds. Furthermore, these results will be used to adjust the CERES retrievals on a individual basis within a collocated CERES broadband radiance footprint to the help develop a much more realistic vertical profile of clouds associated with each CERES radiance measurement. Those profiles will yield the most accurate vertical profiles of cloud radiative heating, to date, over the globe.

\section{ACKNOWLEDGMENTS}

This research is sponsored by the NASA Earth Enterprise System through the CERES, NEWS, CloudSat, and CALIPSO Projects.

\section{REFERENCES}

1. Wielicki, B. A., et al., 1998, Clouds and the Earth's Radiant Energy System (CERES): Algorithm overview. IEEE Trans. Geosci. Remote Sens., 36, 1127-1141.

2. Trepte, Q., Y. Chen, S. Sun-Mack, P. Minnis, D. F. Young, B. A. Baum, and P. W. Heck, Scene identification for the CERES cloud analysis subsystem. Proc. AMS $10^{\text {th }}$ Conf. Atmos. Rad., Madison, WI, June 28 - July 2, 169-172, 1999.

3. Sun-Mack, S., Y. Chen, T. D. Murray, P. Minnis, and D. F. Young, Visible clear-sky and near-infrared surface albedos derived from VIRS for CERES. Proc. AMS $10^{\text {th }}$ Conf. Atmos. Rad., Madison, WI, June 28-July 2, 422-425, 1999.

4. Chen, Y., S. Sun-Mack, Q. Z. Trepte, P. Minnis, and D. F. Young, Solar zenith angle variation of clear-sky narrowband albedos derived from VIRS and MODIS. Proc. $11^{\text {th }}$ AMS Conf. Atmos. Rad., Ogden, UT, June 3-7, 152-155, 2002.

5. Chen, Y., S. Sun-Mack, P. Minnis, W. L. Smith, Jr., and D. F. Young, Surface emissivity derived for infrared remote sensing from satellites. Proc. AMS $11^{\text {th }}$ Conf. Satellite Meteorology and Oceanography., Madison, WI, October 15-18, 512-515, 2001.

6. Chen, Y., S. Sun-Mack, Surface spectral emissivity derived from MODIS data. Proc. SPIE Conf. Optical Remote Sensing of Atmosphere and Clouds III, Hangzhou, China, Oct. 23-27, 2002.

7. Minnis, P.. D.P. Kratz, J. A. Coakley, Jr., M. D. King, D. Garber, P. Heck, S. Mayor, D. F. Young, and R. Arduini, 1995: Cloud Optical Property Retrieval (Subsystem 4.1). "Clouds and the Earth's Radiant Energy System (CERES) Algorithm Theoretical Basis Document, Volume III: Cloud Analyses and Radiance Inversions (Subsystem 4)”, NASA RP 1376 Vol. 3, edited by CERES Science Team, pp. 135-176

8. Minnis, P., D. P. Garber, D. F. Young, R. F. Arduini, and Y. Takano, 1998: Parameterization of reflectance and effective emittance for satellite remote sensing of cloud properties. J. Atmos. Sci., 55, 3313-3339. 
9. Platnick, S., J. Y. Li, M. D. King, H. Gerber, and P. V. Hobbs, 2001: A solar reflectance method for retrieving cloud optical thickness and droplet size over snow and ice surfaces. J. Geophys. Res., 106, 15185-15199.

10. Arduini, R. F., P. Minnis, and D. F. Young, 2002: Investigation of a visible reflectance parameterization for determining cloud properties in multi-layered clouds. Proc. $11^{\text {th }}$ AMS Conf. Cloud Physics, Ogden, UT, June 3-7, CD-ROM, p2.4.

11. Winker, D. M., et al. (2006), The CALIPSO mission and initial results from CALIOP, Proc. SPIE, 6409, 640902, doi:10.1117/12.698003.

12. Sun-Mack, S. P. Minnis, Y. Chen, Y. Yi, J. Huang, B. Lin, A. Fan, S. Gibson, and F. Chang, Multilayered Clouds Identification and Retrieval for CERES Using MODIS. Proc. AMS 12th Conf. Atmos. Radiation, Madison, WI, July 10-14, CD-ROM, P4.19.

13 Minnis, P., S. Sun-Mack, Y. Chen, H. Yi, J. Huang, L. Nguyen, and M. M. Khaiyer, 2005: "Detection and retrieval of multi-layered cloud properties using satellite data." Proc. SPIE Europe Intl. Symp. Remote Sens., Remote Sens. Clouds and the Atmos. X, Bruges, Belgium, September 19-22.

14. Chang, F-L, and Z. Li, 2005: A new method for detection of cirrus overlapping water clouds and determination of their optical properties. J. Atmos. Sci., 62, 3993-4009.

15. Minnis, P., P. W. Heck, and E. F. Harrison, 1990: The 27-28 October 1986 FIRE IFO Case Study: Cloud parameter fields derived from satellite data. Mon. Wea. Rev., 118, 2426- 2446.

16. Chakrapani, V., D. R. Doelling, A. D. Rapp, and P. Minnis, 2002: Cloud thickness estimation from GOES-8 satellite data over the ARM SGP site. Proc. 12th ARM Science Team Meeting, April 8-12, St. Petersburg, FL, 14 pp. Available at http://www.arm.gov/publications/proceedings/conf12/extended_abs/chakrapani-v.pdf. 